\title{
aDNA-Analysen zum \\ spätmerowingischen Kinderdoppelgrab unter dem Frankfurter Dom
}

\author{
Jan Cemper-Kiesslich \\ Christina Amory \\ Walther Parson \\ Egon Wamers
}

\begin{abstract}
Zusammenfassung
Im vorliegenden Beitrag wird eine molekulargenetische Analyse der aDNA (Jan Cemper-Kiesslich, Universität Salzburg, sowie Christina Amory und Walther Parson, Medizinische Universität Innsbruck) vorgelegt, die aus mehreren Proben des Gesichtsschädels eines unverbrannten Skeletts im spätmerowingerzeitlichen Kinderdoppelgrab unter der Bartholomäuskirche („Dom“) in Frankfurt am Main gewonnen wurde. Der archäologischen und anthropologischen Analyse zufolge handelt es sich um ein vier- bis fünfjähriges Mädchen aus der Oberschicht in Ostfranken. Vom als Leichenbrand mitbestatteten zweiten, etwa gleichaltrigen Kind konnte keine verwertbare Probe gezogen werden; sein Geschlecht und weitere Charakteristika bleiben unbekannt. Vom Mädchen konnten sowohl ein autosomaler genetischer Fingerabdruck wie auch die gesamte mitochondriale DNA-Sequenz ermittelt werden. Die fragmentarische autosomale DNA erlaubt eine Bestimmung des Geschlechts als weiblich, jedoch nicht von phänotypischen Charakteristika wie etwa der Pigmentation. Auf Basis der mitochondrialen DNA konnte das Mädchen dem heute in Europa weitverbreiteten, bislang auf Westeuropa konzentrierten Haplotyp U5b2a1a zugewiesen werden, der zur alteuropäischen Haplogruppe U5 gehört. Sein bislang seltenes prähistorisches Vorkommen in Zentral- und Osteuropa gestattet jedoch keine weiterführende bio-ethno-geographische Zuordnung des Mädchens.
\end{abstract}

\section{Schlüsselbegriffe}

Franconofurd, spätmerowingerzeitliche Kinderdoppelbestattung, Bartholomäuskirche, alte DNA, biologisches Geschlecht, autosomaler Fingerabdruck, mitochondriale DNA-Sequenz, bio-ethnogeographische Zuordnung, Haplotyp U5b2a1a.

\footnotetext{
Abstract - aDNA Analyses of the Late Merovingian Children's Double Tomb under Frankfurt Cathedral

In this paper we present the results of the DNA analysis (Jan CemperKiesslich, University of Salzburg and Christina Amory \& Walther Parson, Medical University of Innsbruck) of several samples from unburned facial bones recovered from a late Merovingian chamber grave under the Church of St. Bartholomew ("Cathedral") in Frankfurt am Main / Germany, containing two children. According
}

to archaeological and anthropological data, the remains belong to a 4-5-year-old female infant hailing from the upper class society in Eastern Francia. The second individual, of unknown sex and further characteristics but of approximately the same age, consists of cremated bones - hence no suitable sample for DNA analysis was found. We established an autosomal DNA fingerprint as well as a complete mitochondrial DNA sequence for the unburned remains. The DNA results confirmed the biological sex as female - however, the assessment of phenotypical markers such as pigmentation was not feasible due to extensive DNA degradation. The mitochondrial DNA data correspond to haplotype U5b2a1a, currently found all over Europe, with a high concentration in western Europe, and belonging to the ancient European haplogroup U5. Due to the reputed rare occurrence of U5 in prehistoric times, a more detailed bio-ethnic provenancing was not feasible.

\section{Keywords}

Franconofurd, late Merovingian children's double-grave, St. Bartholomew's Church, ancient DNA, sex identification, autosomal DNA fingerprint, mitochondrial DNA sequence, DNA-based provenancing, haplotype U5b2a1a.

\section{Einführung (E. Wamers)}

Der bislang bedeutendste frühmittelalterliche Grabfund im Stadtgebiet von Frankfurt am Main ist das reich ausgestattete spätmerowingerzeitliche Kindergrab unter der Bartholomäuskirche („Dom“). Es wurde im Verlauf der umfangreichen Domgrabungen 1991-1993 von Andrea Hampel (Bodendenkmalpflege Frankfurt) freigelegt und bereits 1994, im Jahr des Stadtjubiläums, zusammen mit den komplexen Baubefunden publiziert. ${ }^{1}$ Das Grab wurde in einem kleinen spätmerowingischen, partiell hypokaustierten Rechteckbau angetroffen, der als domus ecclesiae

1 Hampel 1994, 112-171, bes. 170. 


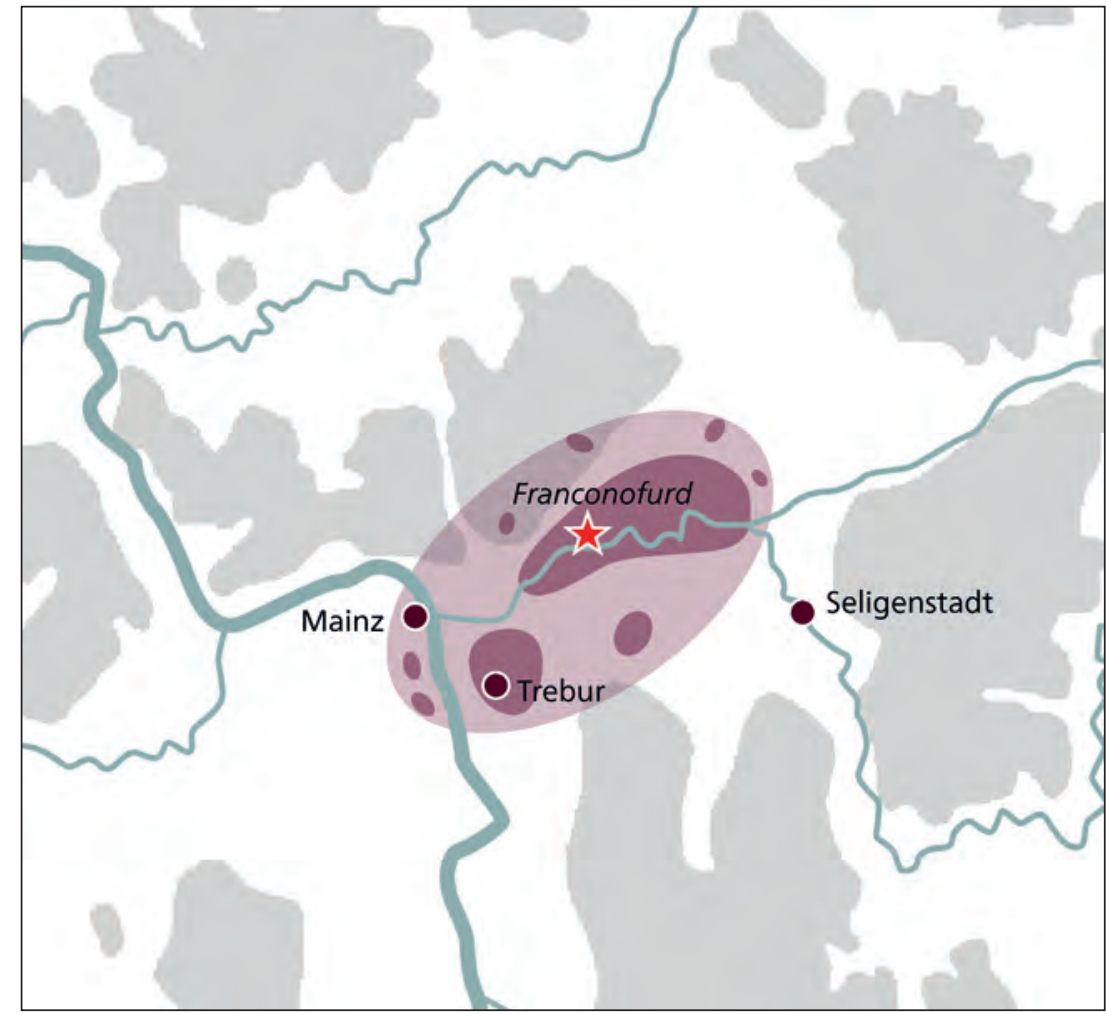

Abb. 1. Fiskalbezirk Frankfurt-Trebur. Die dunklen Flecken markieren das im 8./9. Jh. schriftlich belegte und erschlossene Königsgut (nach Wamers 2015, Abb. 103).

(Klerikerwohnhaus) interpretiert wurde. Weitere Mauerreste des 7./8. Jhs. legen eine ausgedehntere vor- und frühkarolingische Bebauung auf dem Domhügel einschließlich Repräsentationsbauten eines Königshofes nahe. Die villa Franconofurd war laut den Schriftquellen des 8./9. Jhs. Verwaltungszentrum eines von Gelnhausen im Osten bis zur Mainmündung reichenden Fiskalbezirks mit Königsgut (Abb. 1). Aus hochkarolingischer Zeit sind ein Palastbau (aula regia, errichtet 822/823 von Ludwig dem Frommen), eine Pfalzkirche (Salvatorbasilika, errichtet 855 von Ludwig dem Deutschen, Vorgängerbau der heutigen Bartholomäuskirche) $)^{2}$ sowie weitere Stein- und Holzbauten archäologisch nachgewiesen. Die spätere axialsymmetrische Positionierung der Salvatorbasilika auf das reiche Kindergrab, sicher nach Abgang des Rechteckbaus, legt eine bewusste Bezugnahme und damit wohl lang anhaltende Verehrung der Grablege bzw. der hier Bestatteten nahe (Abb. 2). ${ }^{3}$

2 Vgl. die aktuelle Neuauswertung der Grabungsbefunde auf dem Frankfurter Domhügel, die bisherige Literatur berücksichtigend: Ristow 2020.

3 Vgl. Wintergerst 2007, 75-76 und Plan 13/1, 14. - Wamers 2015, 20, 216-218 und Abb. 3.

\subsection{Grabkonstruktion und Bestattungssitte}

In der in einer Ecke des Rechteckbaus eingetieften und mit Holzbohlen abgedeckten Grabkammer befand sich ein Holzsarg, in dem nach dem Kleidungszubehör zu urteilen ein vier- bis fünfjähriges Mädchen körperbestattet worden war; neben ihm im Sarg lag, als Leichenbrand in einem Beutel, ein weiteres, etwa vierjähriges, aber nicht geschlechtsbestimmbares Kind (Abb. 3). Im Leichenbrand befanden sich auch kremierte Krallen (Phalangen) eines Braunbären sowie Tierknochen (Schwein, Schaf/Ziege?). Über beide Kinder war ein Tuch mit aufgenähtem gewebten Goldlahn-Kreuz gebreitet worden - offensichtlich der Ausweis einer christlichen Bestattung. Südlich des Sarges waren in der Grabkammer üppige Speise- und Trankbeigaben samt Glas- und Holzbechern und rheinländischer Drehscheiben-Gefäßkeramik gestellt worden. Ein handgemachter Becher, vermutlich für Brei, ${ }^{4}$ lag unmittelbar neben dem Leichenbrand im Sarg. Die erste Interpretation 1994 deutete die Bestattung als reiche Grablege eines merowingischen Mädchens, den Leichenbrand hingegen als befremdliche Beigaben von „Spielkameraden“ aus kremiertem Kind, Schwein und Bär.

4 Vgl. Косн 2013, 56. 


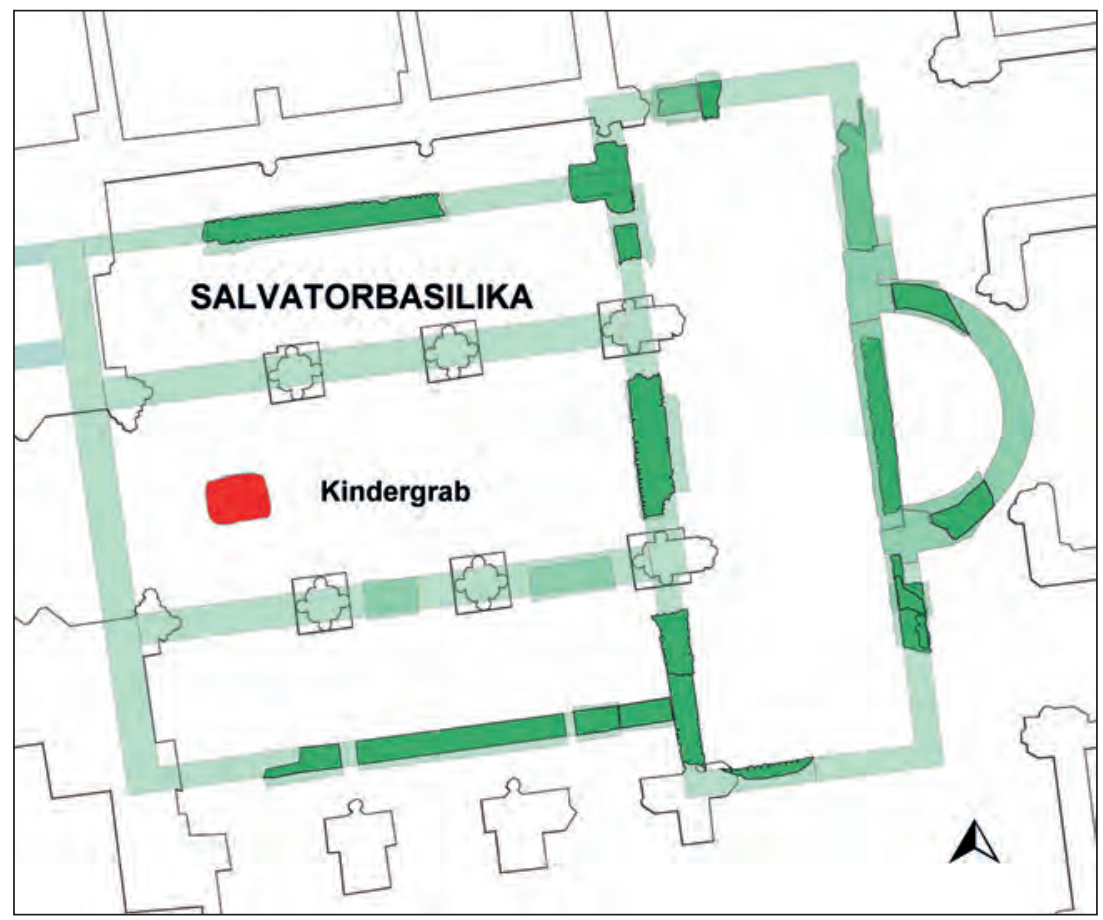

Abb. 2. Lage des Kinderdoppelgrabes (rot) auf der Längsachse im westlichen Hauptschiff der 855 eingeweihten Salvatorbasilika Ludwigs des Deutschen unter der heutigen Bartholomäuskirche in Frankfurt am Main (nach Wintergerst 2007, Plan 14, Ausschnitt. - Zum gerundeten Westabschluss der Salvatorbasilika vgl. die jüngste Rekonstruktion nach RisTow 2020, Abb. 3).

Gut 20 Jahre später wurde vom Autor eine umfangreiche Neuanalyse des enigmatischen Grabes mit zahlreichen archäologischen und naturwissenschaftlichen Einzelstudien vorgelegt. ${ }^{5}$ Grundlegend war dabei die Identifizierung der Grablege als bi-rituelles Kinderdoppelgrab (Körperplus Brandbestattung) in einer ehemaligen domus ecclesiae (Klerikerwohnhaus). Die Lebens- und Beisetzungszeit konnte durch ${ }^{14} \mathrm{C}$-Analysen und vor allem formenkundlich-archäologisch auf das erste Drittel des 8. Jhs. bestimmt werden.

Die extrem reichen Beigaben des unverbrannten Kindes (u. a. Pektorale, Bommelohrringe, Fibeln, Arm- und Fingerringe, ferner Riechdose, Gürtelkette mit Elfenbeinamulett, Nähzubehör, zahlreiche, teils kostbare Textilien) sind zum Teil wegen ihrer zierlichen sowie eigens reduzierten Größe offenkundig individuell und ad personam gefertigt (auch die Drehscheibengefäße für die Speisebeigaben stellen Kleinausgaben üblicher Typen dar). Überwiegend können sie dem spätmerowingisch-frühkarolingischen Typenspektrum der Rheinlande und Alamanniens zugewiesen

5 Wamers 2015, hier alle Detailuntersuchungen mit ausführlicher Literatur. werden. Danach gehörte das Mädchen zur spätmerowingerzeitlichen Oberschicht, wahrscheinlich aus der Familie des Verwalters (actor dominicus/iudex) des fränkischen Königshofs Franconofurd auf dem Domhügel. Vermutlich war das Kindergrab Bestandteil eines Separatfriedhofs auf dem Domhügel mit weiteren reichen Bestattungen, wie sie für die späte Merowingerzeit charakteristisch sind. Weitere beigabenlose Gräber des 7. bis 9./10. Jhs. wurden im Umkreis des Kindergrabes angetroffen. Einige wenige Objekte wie der einzeilige Kamm im Futteral, das Nähzubehör und ein D-Brakteat von der Halskette lassen - trotz ihrer untergeordneten Rolle gegenüber den anderen Beigaben - auch Beziehungen nach Mittel- und Norddeutschland sowie Südskandinavien erkennen.

Das zweite, im Sarg mitbestattete Kind hat andere ethnisch-kulturelle Bezüge: Die Brandbestattung mit Bärenfell ist eine seit Jahrhunderten ausgeübte, typisch skandinavische Sepulkralsitte, die vorwiegend von den Oberschichten gepflegt wurde; das vierjährige Kind dürfte aus einer ebenfalls sozial hochstehenden skandinavischen Familie stammen. Für das 6./7. Jh. gibt es zahlreiche archäologische Hinweise auf Nordleute, die auf dem Kontinent - vorwiegend 

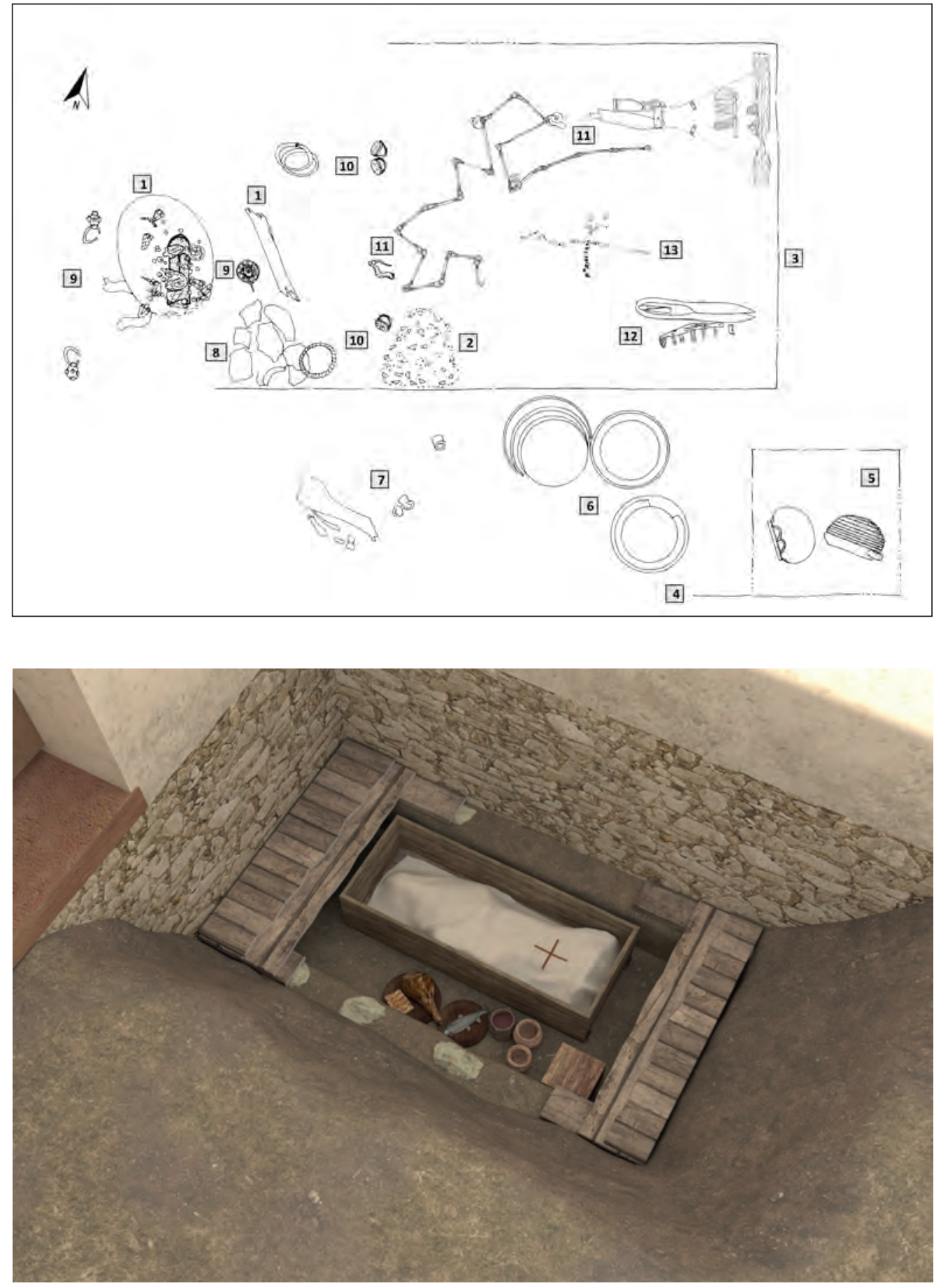

Abb. 3. Plan und Rekonstruktion des Grabes.

a. Grabplan des Kindergrabes (nach Hampel 1994). - 1. Schädel und Armknochen des unverbrannten Kindes. - 2. Knochenbrandnest (in einem organischen Beutel?) mit Resten des zweiten Kindes, von Bärenkrallen sowie Schweine- und anderen Tierknochen. - 3. Sarg. - 4. Südlicher Rand der Grabgrube. - 5. Holzkiste mit Glasund Holzbecher. - 6. Gefäßbeigaben. - 7. Fleisch- und Fischbeigaben. - 8. Freigeformtes Gefäß. - 9. Unter und neben dem Schädel Ohr- und Pektoralschmuck. - 10. Finger- und Armringe. - 11. Elfenbeinanhänger mit Messer an Gürtelkette. - 12. Bündel aus Schere, Nadelbüchse und Kamm. - 13. Gewebtes Goldlahn-Kreuz vom Grabtuch.

b. Blick von Westsüdwest in die holzverschalte Grabkammer mit Sarg und im Süden abgestellten Speise- und Trankbeigaben (Rekonstruktionsvorschlag: E. Wamers, Ausführung: Architectura Virtualis Darmstadt). 


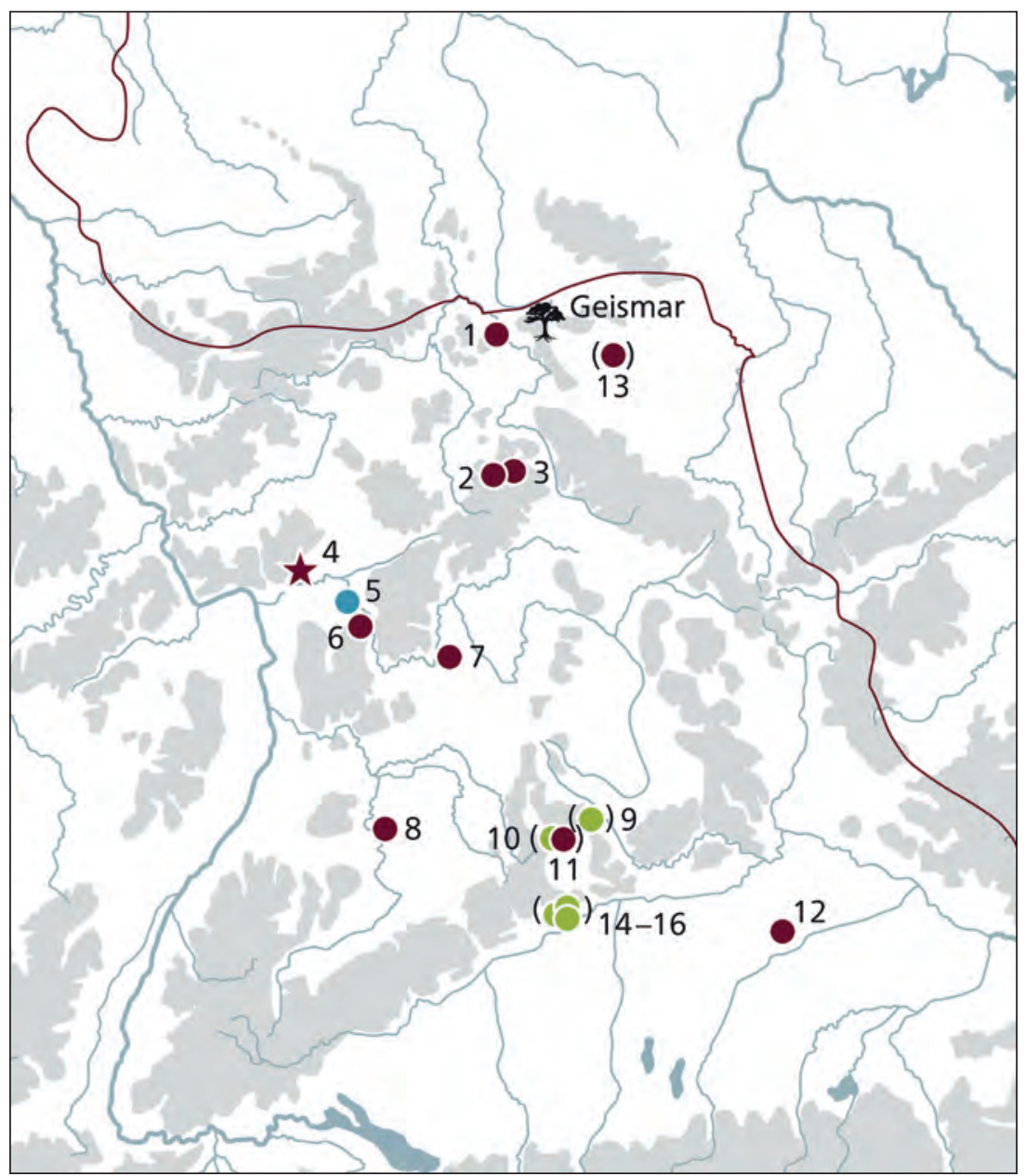

Abb. 4. Verbreitung der bi-rituellen Bestattungen des 6. bis 8. Jhs. - 1. Eschwege-Niederhone. -2. Kaltenwestheim. - 3. Kaltensundheim. - 4. Frankfurt am Main. - 5. Kleinwelzheim. 6. Wenigumstadt. - 7. Kleinlangheim. - 8. Hessigheim. - 9. Dittenheim. - 10-11. Westheim. 12. Ergolding. -13. Urleben. -14-16. Schretzheim. - Grün: 6. Jh.; rot: 7./8. Jh.; blau: undatiert; Klammern: unsichere Befunde; rote Linie: Grenze des Merowingerreiches (nach WAMERS 2015, Abb. 100).

östlich des Rheins - siedelten, vermutlich auch in Familienverbänden. ${ }^{6}$

Die Frankfurter Grablege aus tiefem Kammergrab, „überreichen “7 Speisebeigaben sowie Doppelgrab mit Körper- und Brandbestattung verbindet die Grablege mit thüringischen und anderen, „ethnisch“-kulturell nicht näher bestimmbaren Bestattungen rechts des Rheins (Abb. 4). Auch bei ihnen sind skandinavische Bezüge sowie fortlebendes, eventuell wieder reaktiviertes Heidentum sichtbar. Gleichzeitig ist in den 720er-Jahren die Region zwischen Nordhessen, Westthüringen, dem Untermaingebiet samt

6 Z. B. КосH 1999. - Wamers 2015, 186-193.

7 Dazu Sippel 1989, 377.
Wetterau sowie den Mainlanden das Aktionsfeld von Bonifatius, der im Auftrag der fränkischen Expansionsmacht eine Neumissionierung der in „verwildertem Christentum“8 Lebenden samt kirchlicher Neuorganisation durchführen sollte, wofür die Fällung des Baumheiligtums Jupiter-Eiche („Donar-Eiche“) bei Geismar das augenfälligste Symbol war. Diese „synkretistische“, durch das Nebeneinander von heidnischen und christlichen Praktiken und Ritualen geprägte Phase spiegelt sich im Kinderdoppelgrab, das durch das kreuzverzierte Grabtuch eine christliche Signierung erfuhr und vermutlich eine besondere memoriale Verehrung genoss, die eineinhalb Jahrhunderte später dazu führte, dass

8 KRUtZLER 2009, 269-271. 


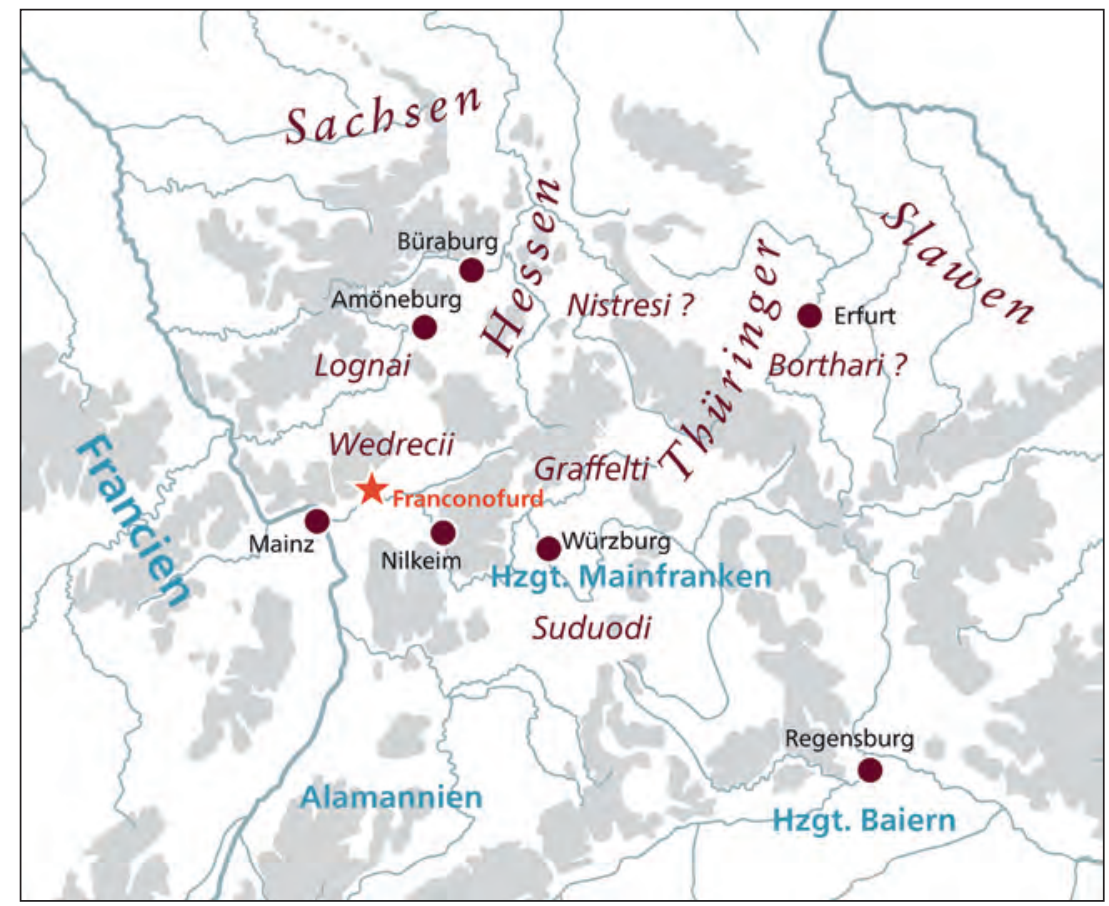

Abb. 5. Ostfranken 700/730 n. Chr. Ethnien, von den Franken abhängige Herzogtümer sowie Völkerschaften laut Brief von Papst Gregor III. an „die Edlen und das Volk der Provinzen Germaniens“ (nach Wamers 2015, Abb. 102).

das Grab einen zentralen Platz in der Pfalzkapelle Ludwigs des Deutschen in seiner „Hauptstadt“9 Frankfurt erhielt. Doch die mageren historischen Quellen erlauben nur eine begrenzte Rekonstruktion der politischen, kulturhistorischen und religiösen Verhältnisse der Gebiete und Länder östlich des Rheins und insbesondere des Untermaingebietes im 7. und 8. Jh., der Zeit der frühkarolingischen politischen „Gleichschaltung“ (Abb. 5). ${ }^{10}$

Für diese Umbruchphase scheint das exzeptionelle „bi-rituelle Kinderdoppelgrab“ ein Schlüsselfund zu sein. Weiterführende Antworten, etwa auf die Frage nach dem Hintergrund der engen Beziehung der beiden Kleinkinder zueinander, einer möglichen Verwandtschaft oder ihrer biologischen, eventuell ethnischen Zugehörigkeit, konnten auch naturwissenschaftliche Untersuchungen (Anthropologie, ${ }^{14} \mathrm{C}$ - und Isotopenanalysen) nur in sehr begrenztem Umfang geben (Abb. 6). ${ }^{11}$ Zusätzliche Aufschlüsse wurden

9 Hartmann 2002, 83.

10 Dazu zuletzt zusammenfassend mit dem Versuch einer Synopse: WAMERs 2015, 199-211.

11 Beiträge von N.-J. Rebach, E. Wamers, M. HüLs, M. SchweIsSING, in: WAMERs 2015, 39-50. - Bereits 1993/1994 hatte der Biologe Erwin Hahn erste „anthropologische Kurzbestimmungen von ausgewählten Skelettresten“ durchgeführt (in: Hampel 1994, 233, hier fälschlich J. Hahn). von einer molekulargenetischen Analyse der Alt-DNA der Kinder erhofft, die jedoch erst nach Erscheinen der Neupublikation 2015 angegangen werden konnte. Die Ziele der Untersuchungen, die an den Universitäten Salzburg und Innsbruck durchgeführt wurden, ${ }^{12}$ waren die Geschlechtsdiagnose, die Rekonstruktion einer eventuellen biologischen Verwandtschaft, eine Verortung des bio-ethno-geographischen Hintergrundes der Kinder sowie eine DNA-basierte phänotypische Charakteristik.

2. Molekularbiologische Untersuchungen (J. Cemper-Kiesslich, C. Amory, W. Parson)

\subsection{Methodik und Verfahren}

Für die molekulararchäologischen Analysen wurden in den Jahren 2015 und 2017 zwei unabhängige Sets an Proben von den oben beschriebenen Skelettresten des unverbrannten Kindes (Abb. 6) genommen. Nach sorgfältiger Autopsie

12 Prof. Dr. Jan Cemper-Kiesslich, Universität Salzburg (IFFB Gerichtsmedizin und FB Altertumswissenschaften), MSc Christina Amory (vormals Strobl) und Prof. Dr. Walther Parson (beide Medizinische Universität Innsbruck, Institut für Gerichtsmedizin). Herrn Cemper-Kiesslich sowie der Co-Autorin Christina Amory und dem Co-Autor Walther Parson bin ich für die aufwändigen und dabei honorar- und kostenfreien Untersuchungen überaus dankbar. 


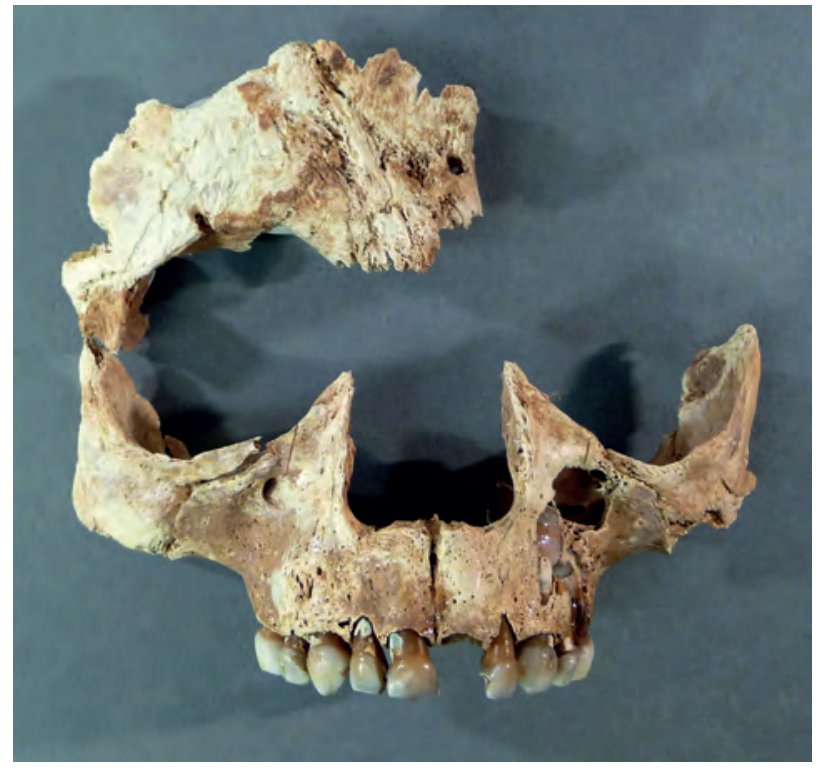

Abb. 6. Fragmentarischer Gesichtsschädel des unverbrannten Mädchens in Frontalansicht (Länge 8,9 cm). Die Geschlechtsbestimmung war anthropologisch nicht möglich, sondern erfolgte anhand der Beigaben. Sie wurde später durch die aDNA-Analysen bestätigt (Foto: Archäologisches Museum Frankfurt).

erwiesen sich die kremierten Reste der Brandbestattung für eine erfolgversprechende Probenentnahme leider als nicht mehr geeignet.

- Set 1 (2015): ein Fragment des Fersenbeines (fraglich), ein Stück des Unterkiefers, ein Oberkieferfragment sowie ein Felsenbein (Pars petrosa);

- Set 2 (2017): eine Probe von der Schädelkalotte, vom Hinterhauptsbein (Os occipitale), eine weitere Probe vom Felsenbein sowie vom Augenhöhlendach.

Sämtliche DNA-Untersuchungen wurden in zugangsbeschränkten Laborbereichen, die für eine DNA-Spurenanalyse ausgelegt sind, durchgeführt; bei der Bearbeitung historischer Proben wurde stets eine räumliche und zeitliche Trennung zwischen der Untersuchung alter DNA (Knochenproben) und moderner DNA (Vergleichsproben, Gelegenheitspersonen) eingehalten. Um Kontaminationen im Labor während der Bearbeitung zu vermeiden, wurden für sämtliche Prä-PCR-Arbeiten ausschließlich zertifiziert DNA/DNAse-freie Einwegmaterialen (Probenröhrchen) und sog. aerosol barrier tips (Pipettenspitzen mit einer physikalischen Barriere, die eine Instrumentenkontamination/Verschleppung durch die Pipetten ausschließt) verwendet. Sämtliche Reagenzien und Kits wurden vor der Verwendung auf die Anwesenheit potentiell kontaminierender menschlicher DNA kontrolliert und freigegeben.
Wiederverwendbares Werkzeug (Fräsen und dergleichen) wurde vor dem Einsatz in einer Laborspülmaschine gereinigt und anschließend 48 Stunden bei $200^{\circ} \mathrm{C}$ hitzesterilisiert und somit DNA-frei gemacht. ${ }^{13}$

Aus konservatorischen Gründen wurde minimalinvasiv beprobt, nachdem die Oberfläche der Knochenfragmente an der Beprobungsstelle physikalisch mit einer DNA-freien Drahtbürste bzw. Fräse abpräpariert wurde, um etwaig anhaftendes biologisches Material Dritter („Gelegenheitspersonen“ oder „Kontaktpersonen“, vgl. oben) zu entfernen.

Je $250 \mathrm{mg}$ Knochenpulver wurden in $650 \mu \mathrm{l}$ EDTALösung $^{14}$ dekalzifiziert, Proteine mittels ProteinaseK abverdaut und nach einer Standardmethode ${ }^{15}$ aufgereinigt und konzentriert. Nach Quantifizierung ${ }^{16}$ zeigten sich DNA-Mengen im Konzentrationsbereich von einigen wenigen Picogramm $/ \mu$ l gereinigter DNA, was in etwa der DNA-Menge in einer menschlichen Zelle entspricht. Die Quantifizierungsanalyse erlaubt außerdem die Berechnung eines sogenannten Degradationsindex, eines Wertes, der Auskunft über die molekulare Integrität der untersuchten Probe gibt - im vorliegenden Fall konnte für die meisten Proben eine mäßige bis deutliche Degradation festgestellt werden, was bei dem gegebenen postmortalen Intervall plausibel erscheint. Für die Darstellung autosomaler ${ }^{17}$ und Y-chromosomaler DNA-Profile wurden forensische Standard-Kits ${ }^{18}$ mit erhöhter Nachweisempfindlichkeit verwendet. Die Sequenzierung der mitochondrialen DNA erfolgte nach Parson et al. ${ }^{19}$ bzw. Strobl et al. ${ }^{20}$

13 Das hier beschriebene Verfahren wurde speziell im untersuchenden Labor der Gerichtsmedizin Salzburg entwickelt und hat sich über 20 Jahre als verlässliches Mittel zur sicheren Dekontamination wiederverwendbarer Metall- und Glasgeräte bewährt; vgl. auch Cemper-Kiesslich, Neuhuber, Schwarz 2010.

14 Ethylendiamintetraacetat (EDTA) ist ein sog. Chelatbildner, welcher in wässriger Lösung $\mathrm{Ca}^{++}$und $\mathrm{Mg}^{++}$-Ionen zu binden vermag. Folglich handelt es sich um ein probates Agens zur schonenden Auflösung der mineralischen Knochenmatrix und ist geeignet, um allenfalls enthaltene DNA störungsfrei in die Lösung freizusetzen.

15 Cemper-Kiesslich, Schwarz, Neuhuber 2011.

16 Herstellermanual: QuantifilerTM Trio revision G, applied biosystems by life technologies (2017).

17 D. h. beim Menschen auf den Chromosomen 1-22 befindliche Merkmale (im Gegensatz zu sog. gonosomalen Merkmalen, die auf dem X-bzw. Y-Chromosom lokalisiert sind).

18 AmpFISTR ${ }^{\circledR}$ NGM SElectTM PCR Amplification Kit user guide. revision F, applied biosystems by life technologies (2015), AmpFISTR $®$ Identifiler ${ }^{\circledR}$ Plus PCR Amplification Kit user guide. 03/2012 applied biosystems by life technologies (2012) und AmpFISTR $®$ Yfiler® Plus PCR Amplification Kit user guide. revision C, applied biosystems by life technologies (2016).

19 Parson et al. 2013.

20 Strobl et al. 2018. 
Im Sinne einer Arbeits-/Erwartungshypothese sind wir davon ausgegangen, im Erfolgsfall ein weibliches Individuum über die DNA-Befunde identifizieren $\mathrm{zu}$ können. Überraschenderweise fanden sich in dem Untersuchungsmaterial an einer Probe (Pars petrosa) ein weibliches und immerhin an zwei weiteren Proben (einem Teil der Schädelkalotte sowie am Os occipitale) ein übereinstimmendes männliches DNA-Profil. Sämtliche Befunde (DNA-Profile) konnten über teilweise überlappende Merkmalskombinationen (vgl. Anm. 18) verifiziert bzw. bestätigt werden, für das identifizierte männliche Individuum wurde überdies ein Y-chromosomaler Haplotyp erstellt.

In der auf diesen Befund folgenden Diskussion der $\mathrm{Au}-$ torin und der Autoren konnten alternative Hypothesen (Transfer von Probenmaterial aus der oben angesprochenen Brandbestattung bzw. Doppelbestattung im Körpergrab) rein aus anthropologisch-archäologischen Gründen praktisch ausgeschlossen werden - jene Proben mit dem männlichen DNA-Profil stammten alle vom gleichen archäologischen Individuum (dem „Mädchen“) und zeigten auch keinerlei Spuren von Brandeinwirkung. Folglich schien die Hypothese einer Kontamination durch eine der bearbeitenden Personen die plausibelste Erklärung, allerdings fand sich unter den zunächst insgesamt 13 untersuchten potentiellen Kontaminatorinnen und Kontaminatoren kein zu den Befunden der Knochen passendes Profil. Schließlich konnten beim contact tracing durch Egon Wamers noch zwei weitere männliche Gelegenheitspersonen namhaft gemacht werden, die zur Zeit der Ausgrabungen und Magazinierungen mit dem Untersuchungsmaterial Kontakt hatten; einer war gerne bereit, seine DNA zu Vergleichszwecken zur Verfügung zu stellen, der andere war - bedauerlicherweise zum Zeitpunkt gegenständlicher Untersuchung verstorben, sein Sohn stellte jedoch freundlicherweise Referenzmaterial zur Verfügung. So konnte das männliche Profil letztendlich einer männlichen „Kontaktperson“ zugeordnet werden, welche die Knochen des Mädchens zuletzt 20 Jahre vor der hier berichteten Analyse in (vermutlich unbehandschuhten) Händen hielt: Es handelt sich um den anthropologischen Erstbearbeiter Erwin Hahn (vgl. oben Anm. 11). Ausgesprochen bemerkenswert erscheint hier der Umstand, dass die molekulare Charakteristik der kontaminierten Proben (DNA-Ausbeute, Degradationsindex, Qualität der Ergebnisse etc.) jener einer authentischen historischen Probe entspricht. ${ }^{21}$

21 Eine einschlägige Publikation von Cemper-Kiesslich, Amory, Parson und Wamers wird in Kürze in der Rubrik „Lessions from the Museum“ - ein Kurzformat in FSMP („Forensic Science, Medicine and Pathology") - erscheinen.
Ergänzende Anmerkungen zur Qualitätssicherung und Datenauthentifizierung: ${ }^{22}$ Jenseits der oben beschriebenen Vorbeugemaßnahmen (Vermeidung von Kontaminationen) wird jedem DNA-Befund aus historisch-archäologischem Untersuchungsmaterial ein Mehrstufenmodel zur Qualitätssicherung zugrunde gelegt: Zunächst dürfen sämtliche Leerextrakte und Negativkontrollen keine nachweisbare DNA enthalten, alle mitgeführten Positivkontrollen müssen den Soll-Wert ergeben. Stets werden mehrere Proben eines Individuums in getrennten Analysegängen untersucht (hier sogar in zwei unabhängigen Tranchen), Ergebnisse werden folglich nur als authentisch betrachtet, wenn zumindest zwei der erfolgreich analysierten Proben keine widersprüchlichen Ergebnisse zeitigen. Allfällige Ergebnisse dürfen nicht mit einer der Gelegenheitspersonen übereinstimmen; dazu sei angemerkt, dass die Namhaftmachung von Gelegenheitspersonen speziell bei sog. „Altfunden“ - also bei Untersuchungsmaterial, bei dem zum Zeitpunkt der Bergung noch keine DNA-Analyse in Aussicht war - mit größeren Problemen behaftet sein kann, was im Rahmen dieser Studie deutlich wurde. Idealerweise wird bereits vor Aufnahme der Grabungstätigkeit das gesamte Grabungsteam über die Gefahr von Kontaminationen bei unsachgemäßer Handhabung informiert und bei der Bergung (menschlicher) biogener Überreste nur ein eingeschränkter, speziell geschulter Personenkreis mit den Arbeiten betraut. ${ }^{23}$

Für die weiteren Betrachtungen sei festgehalten, dass auch für das weibliche DNA-Profil, das aus einer der untersuchten Proben gewonnen werden konnte, keine 100\%ige Sicherheit hinsichtlich der Authentizität gegeben werden kann, außer eben, dass keine der möglichen weiblichen Kontakt- oder Gelegenheitspersonen übereinstimmt gleichwohl eine wohlbegründete Ausschlussdiagnose.

Im Sinne des oben referenzierten Mehrstufenmodells zur Qualitätssicherung wäre der Nachweis einer biologischen Verwandtschaft (beispielsweise innerhalb einer Grabgruppe) als der Gold-Standard zu sehen, muss hier aber aus naheliegenden und prinzipiellen Gründen ausbleiben. Eine algorithmisch basierte Einschätzung der Authentizität der berichteten Daten ${ }^{24}$ konnte aufgrund der angewandten Untersuchungstechniken (vgl. oben) nicht durchgeführt werden, da hierfür Datensätze basierend auf dem sog. MPS/NGS (massive parallel sequencing / next generation sequencing) vonnöten sind. Diese Methode basiert auf bekannten Degradationsmustern alternder DNA

22 Vgl. Cemper-Kiesslich, Neuhuber, Schwarz 2010.

23 Vgl. z. B. Cemper-Kiesslich et al. 2021.

24 Renaud et al. 2015. 


\begin{tabular}{|l|l|}
\hline $\begin{array}{l}\text { Merkmal nach AmpFISTR® Identifiler } \\
\text { und/oder AmpFISTR } ® \text { NGM SElect }\end{array}$ & $\begin{array}{l}\text { Genotyp - Mädchen - S151831 - } \\
\text { basierend auf D052536 }\end{array}$ \\
\hline D8S1179 - idiP \& NGM & $10 / 13$ \\
\hline D21S11 - idiP \& NGM & $29 / 31.2$ \\
\hline D7S820 - idiP & $8 / 10$ \\
\hline CSF1PO - idiP & $12 / 12$ \\
\hline D3S1358 - idiP \& NGM & $15 / 16$ \\
\hline TH01 - idiP \& NGM & $6 / 8$ \\
\hline D13S317 - idiP & $11 / 12$ \\
\hline D16S539 - idiP \& NGM & $9 / 11$ \\
\hline D2S1338 - idiP \& NGM & $19 / 24$ \\
\hline D19S433 - idiP \& NGM & $14 / 14$ \\
\hline vWA - idiP \& NGM & $18 / 19$ \\
\hline TPOX - idiP & $8 / 11$ \\
\hline D18S51 - idiP \& NGM & $15 / 17$ \\
\hline AMEL - idiP \& NGM & X/X \\
\hline D5S818 - idiP & $11 / 12$ \\
\hline FGA - idiP \& NGM & $21 / 22$ \\
\hline D10S1248 - NGM & $13 / 15$ \\
\hline D22S1045 - NGM & $11 / 15$ \\
\hline D2S441 - NGM & $11 / 14$ \\
\hline D1S1656 - NGM & $15.3 / 17.3$ \\
\hline D12S391 - NGM & $20 / 22$ \\
\hline SE33 - NGM & $((27.2)) / ?$ \\
\hline & \\
\hline
\end{tabular}

Tab. 1. Autosomale Merkmalskombination („DNA-Fingerabdruck“) für die Körperbestattung („Mädchen“) im Frankfurter Kinderdoppelgrab.

und damit verbundenen Änderungen in der Nukleinsäuresequenz. Ein Befund aus archäologischem Probenmaterial wird mit einem „Erwartungswert“ in Beziehung gesetzt bzw. verglichen und daraus ein Maß für die wahrscheinliche Authentizität berechnet - folglich handelt es sich sicher um einen sehr wertvollen Ergänzungsbefund, jedoch keinen letztgültigen Beweis. Zudem bleibt diskussionswürdig, ob die hier berichtete und mit an Sicherheit grenzende Wahrscheinlichkeit aufgezeigte „historische“ Kontamination bzw. die dieser zugrunde liegende DNA nicht die gleichen Degradationsmuster aufweist wie eine von oben genanntem Algorithmus als „authentisch alt“ klassifizierte Datenlage.

Auch wenn eine systematische Beprobung der Pars petrosa von manchen Wissenschaftlern und Wissenschaftlerinnen (insbesondere hinsichtlich der DNA-Ausbeute und der Qualität der selbigen) als sehr vielversprechend beschrieben wird ${ }^{25}$ und diese Beobachtung auch von uns

25 Pinhasi et al. 2015.
- nicht zuletzt in dieser Studie - bestätigt wurde, sei kritisch angemerkt, dass dadurch eine nachhaltige Zerstörung von einzigartigem Untersuchungsmaterial in Kauf genommen wird bzw. werden muss.

\subsection{Ergebnisse der autosomalen DNA-Analyse}

Tab. 1 bildet einen insgesamt 21 autosomale (vgl. Anm. 17) Merkmale umfassenden sog. genetischen Fingerabdruck sowie den Geschlechtsmarker Amelogenin (AMEL) ab - somit ist die archäologische Identifizierung der Bestattung als „Mädchengrab“ über die (molekular-)biologische Geschlechtsdiagnose verifiziert. Die angegebenen Zahlenwerte entsprechen bestimmten definierten Längenverhältnissen in der menschlichen DNA, die eine Person hochgradig individualisieren und die Bestimmung von familiären Verwandtschaftsverhältnissen (Elternschaft, Geschwisterschaft) erlauben und auf eine einzelne Person zutreffen (es wurden keine zusätzlichen Merkmale gefunden, die auf eine 


\begin{tabular}{|c|c|c|c|c|c|c|}
\hline$\Delta \mathrm{rCRS}$ & $\Delta \mathrm{rCRS}$ & $\Delta \mathrm{rCRS}$ & $\Delta \mathrm{rCRS}$ & $\Delta \mathrm{rCRS}$ & $\Delta \mathrm{rCRS}$ & $\Delta \mathrm{rCRS}$ \\
\hline $73 G$ & $150 \mathrm{~T}$ & $263 G$ & $315.1 \mathrm{C}$ & $750 \mathrm{G}$ & $1438 \mathrm{G}$ & $1721 \mathrm{~T}$ \\
\hline$\Delta \mathrm{rCRS}$ & $\Delta \mathrm{rCRS}$ & $\Delta \mathrm{rCRS}$ & $\Delta \mathrm{rCRS}$ & $\Delta \mathrm{rCRS}$ & $\triangle \mathrm{rCRS}$ & $\Delta \mathrm{rCRS}$ \\
\hline $2206 \mathrm{~T}$ & $2706 \mathrm{G}$ & $3197 \mathrm{C}$ & $4732 \mathrm{G}$ & $4769 \mathrm{G}$ & $7028 \mathrm{~T}$ & $7768 \mathrm{G}$ \\
\hline$\Delta \mathrm{rCRS}$ & $\Delta \mathrm{rCRS}$ & $\Delta \mathrm{rCRS}$ & $\Delta \mathrm{rCRS}$ & $\Delta \mathrm{rCRS}$ & $\Delta \mathrm{rCRS}$ & $\Delta \mathrm{rCRS}$ \\
\hline $8281 \mathrm{del}$ & $8282 \mathrm{del}$ & $8283 \mathrm{del}$ & 8284del & $8285 \mathrm{del}$ & 8286del & $8287 \mathrm{del}$ \\
\hline$\Delta \mathrm{rCRS}$ & $\Delta \mathrm{rCRS}$ & $\Delta \mathrm{rCRS}$ & $\Delta \mathrm{rCRS}$ & $\Delta \mathrm{rCRS}$ & $\Delta \mathrm{rCRS}$ & $\Delta \mathrm{rCRS}$ \\
\hline $8288 \mathrm{del}$ & 8289del & $8860 \mathrm{G}$ & $9477 \mathrm{~A}$ & $9804 \mathrm{~T}$ & $11467 \mathrm{G}$ & $11719 \mathrm{~A}$ \\
\hline$\Delta \mathrm{rCRS}$ & $\Delta \mathrm{rCRS}$ & $\Delta \mathrm{rCRS}$ & $\Delta \mathrm{rCRS}$ & $\Delta \mathrm{rCRS}$ & $\Delta \mathrm{rCRS}$ & $\Delta \mathrm{rCRS}$ \\
\hline $12308 \mathrm{G}$ & $12372 \mathrm{~A}$ & $13617 \mathrm{C}$ & $13637 \mathrm{G}$ & $14182 \mathrm{C}$ & $14766 \mathrm{~T}$ & $15326 \mathrm{G}$ \\
\hline$\Delta \mathrm{rCRS}$ & $\Delta \mathrm{rCRS}$ & $\Delta \mathrm{rCRS}$ & & & & \\
\hline $15511 \mathrm{C}$ & $16184 \mathrm{~T}$ & $16213 \mathrm{~A}$ & & & & \\
\hline
\end{tabular}

Tab. 2. Mitochondrialer Haplotyp des Mädchens im Frankfurter Kinderdoppelgrab.

Mischung bzw. Kontamination hindeuten). Oben abgebildete Datenlage versteht sich zum einen als sog. KonsensusProfil $^{26}$, zum anderen als Komposit-Profil2 ${ }^{27}$, wobei die überlappenden Marker (insgesamt 11) übereinstimmende Ergebnisse zeigten. ${ }^{28}$

Hier sei angemerkt, dass dieses DNA-Profil neben der Geschlechtsdiagnose als Qualitätskriterium (100\%iger Ausschluss aller erfassten Gelegenheitspersonen/Kontaminatoren) eine sehr solide Aussagekraft für die genetische Bestimmung der Bestattung besitzt. Wie bereits angedeutet, kann der Befund aus Tab. 1 als hochvalide Datenbasis für eine Verwandtschaftsrekonstruktion im Falle eines zukünftig weiteren typisierbaren Individuums mit fraglicher biologischer Beziehung zu dem Mädchen fungieren.

\subsection{Ergebnisse der mitochondrialen DNA-Analyse}

Die Angabe des Haplotyps ${ }^{29}$ bezieht sich auf festgestellte Unterschiede $(\Delta)$ zur rCRS ${ }^{30}$ (revised Cambridge Reference

26 D. h., es konnten nicht in jeder Einzelanalyse alle Merkmale nachgewiesen werden; die Einzelbefunde widersprechen einander aber nicht und wurden für die Tabelle zusammengefasst.

27 Die insgesamt 21 Merkmale (15 aus dem Analysekit AmpFISTR ${ }^{\circledR}$ Identifiler $^{\text {TM }}$ PLUS und 16 aus AmpFISTR ${ }^{\circledR}$ NGM SElect, jeweils ohne Amelogenin) setzen sich aus 11 überlappenden / in beiden Kits enthaltenen Markern zusammen, dabei sind 5 Marker nur im Identifiler und 6 Marker nur im NGM SElect enthalten.

28 Vgl. dazu auch Helm, Neuhuber, Cemper-Kiesslich 2020.

29 Generell versteht man unter Haplotyp („einfacher Typ“) die individuelle Ausprägung der genetischen Information, die auf nur einem von zwei vorhandenen (autosomalen) Chromosomen zu finden ist. Der Begriff Haplotyp wird aber auch für die Beschreibung von Y-chromosomalen bzw. mitochondrialen Merkmalskombinationen verwendet, da beide beim Menschen uniparental vererbt werden, also von nur einem der beiden Elternteile stammt.

30 ANDrews et al. 1999.
Sequence $)=\Delta$ rCRS. Im Gegensatz zu den in Tab. 1 gelisteten Längenmaßen rekurriert diese Darstellung auf eine Sequenzierung (Auslesen des genetischen Codes im Sinne einer gerichteten Abfolge der vier „DNA-Buchstaben“); das menschliche Mitochondrium umfasst ca. 16.000 dieser Buchstaben, eine schlichte Abbildung der DNA-Sequenz als Text wäre praktisch unlesbar - folglich gibt es die Konvention, sich auf die Unterschiede zu einer standardisierten Referenz-Sequenz (rCRS) zu beschränken.

Im Gegensatz zu den autosomalen Merkmalen (Tab. 1), die in jeder Generation neu kombiniert werden, wird die mitochondriale $\mathrm{DNA}^{31}$ beim Menschen ausschließlich von der Mutter an die Kinder weitergegeben und bleibt - von Mutationsereignissen abgesehen - vom Informationsgehalt her konstant. Folglich besitzen alle Mitglieder einer ungebrochenen weiblichen Linie (Männer und Frauen) den gleichen mitochondrialen Haplotyp; prinzipiell kann also der Befund aus Tab. 2 als Referenz für die Rekonstruktion einer Matrilinie oder aber auch für die Abschätzung der bioethno-geographischen Zugehörigkeit einer Person (bzw. deren weiblicher Linie, wie in diesem Fall) herangezogen werden. Eine entsprechende Abschätzung erfolgt über einen rezenten Referenzdatensatz in der Onlinedatenbank https://empop.online/32: Das Mädchen bzw. sein in Tab. 2 abgebildeter mitochondrialer Haplotyp gehört zu Haplogruppe U5b2a1a. Abb. 7 zeigt eine sog. Heatmap, gleichsam

31 Mitochondrien sind Zellorganellen, die für den Energiestoffwechsel verantwortlich sind. Sie besitzen - im Gegensatz zu anderen Organellen - eine eigene, extranukleäre, d. h. nicht im Zellkern befindliche Erbsubstanz, welche in 100-1000-facher Kopie pro Mitochondrium vorliegt.

32 mtDNA database, v4/R13 (Abfrage 09.12.2020; Aktualisierung ohne Veränderungen 16.08.2021). 


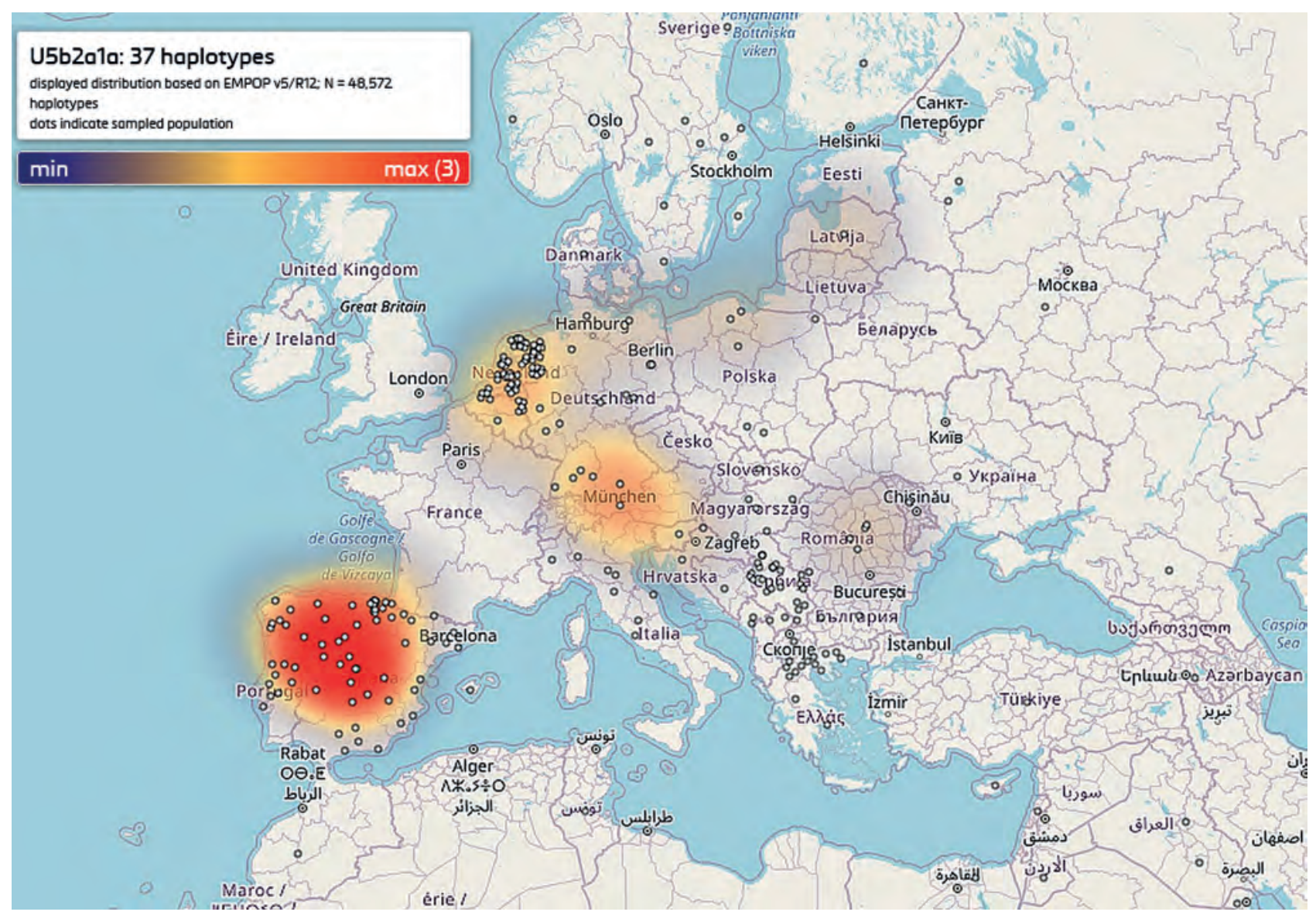

Abb. 7. Heatmap (geographische Häufigkeitsverteilung) der mitochondrialen Haplogruppe U5b2a1a in der rezenten Bevölkerung Westeurasiens und Nordamerikas - Ausschnitt Europa. Die weißen Punkte markieren Orte/Regionen, zu denen mtDNA-Proben vorliegen. Die farbliche Häufigkeitsinzidenz der Haplogruppe U5b2a1 a bezieht sich nur auf den westeurasischen Anteil von insgesamt 37 Treffern (Screenshot von https://empop.online/ [25.09.2020; Aktualisierung ohne Veränderungen 16.08.2021]).

eine Häufigkeitsverteilung in der rezenten Bevölkerung Europas.

Diese Karte stellt nur einen Ausschnitt der beutigen b3 $^{33}$ Gesamtverbreitung dieses Haplotyps in Westeurasien und Nordamerika dar, wobei die Gesamtzahl aller bislang nachgewiesenen Haplogruppen-Treffer lediglich 37 ausmacht (bei einer Gesamtgröße der Datenbank von 48.572 Einträgen zum Zeitpunkt der Abfrage). Bei den nordamerikanischen Vorkommen dieser typisch westeurasischen Haplogruppe handelt es sich um Nachfahren europäischer Auswanderer. Die Haplogruppe U5b2a1a ist praktisch in ganz Europa zu finden (gelbliche Spots = 1-2 Fälle); der rote „Hotspot“ auf der Iberischen Halbinsel zeigt nur

3з CAVE: Bei der Verortung historischer DNA-Merkmale (provenancing) ist bei der Bewertung größte Zurückhaltung geboten schließlich liegen zwischen den Referenzdaten und der Lebenszeit des Frankfurter Mädchens etwa 1300 Jahre. drei Fälle an. Die übergeordnete Haplogruppe U5 dürfte eine der ältesten Europas sein, wobei - aus prähistorischer Sicht - U5b2a1a charakteristisch für zentral- und osteuropäische Populationen ist. ${ }^{34}$ Relativ selten findet sich diese Haplogruppe in Finnland, ${ }^{35}$ wohingegen in der Ukraine (Vapnyarka) ein naher Haplotyp (U5b2a1a2) bei einem eisenzeitlichen skythischen Individuum gefunden werden konnte, ${ }^{36}$ exakte Übereinstimmungen liegen mit einem Individuum der mitteleuropäischen Lengyel-Kultur ${ }^{37}$ aus der Brześć-Kujawski-Gruppe (neolithisch, ca. 4230 Jahre BP) und einem weiteren mittelneolithischen Individuum ${ }^{38}$ (ca. 5370 Jahre BP) aus Krusza Zamkowa, Polen, vor.

\footnotetext{
34 Malyarchuk et al. 2010.

35 Oversti et al. 2017.

36 JuRAs et al. 2017b.

37 Chylenski et al. 2017.

38 JURAs et al. 2017a.
} 
Zwar gibt es aus dem frühen Mittelalter, also dem Zeitraum, in dem das Mädchen gelebt hat (nach kalibrierter Radiokarbondatierung spätes 7., nach archäologischer Datierung frühes 8 . Jh. n. $\mathrm{Chr}^{39}$ ), bereits erste systematische DNA-Befunde aus Ungarn und Italien, doch findet sich der Haplotyp des Mädchens dort nicht wieder. ${ }^{40}$

Auch wenn die forensische DNA-Analytik mittlerweile eine Abschätzung bestimmter phänotypischer Charakteristika wie zum Beispiel Haar- oder Augenfarbe an moderner (d. h. „frischer") DNA ermöglicht, ${ }^{41}$ so war ein Versuch, die DNA des Mädchens analog dazu auszuwerten, aufgrund des hohen Degradationsgrades der extrahierten Erbsubstanz zur Zeit der Laborarbeiten nicht realisierbar. Jüngere Entwicklungen in der Analytik geben jedoch die begründete Hoffnung, dass sich dieser Befund in näherer Zukunft noch einholen lässt. ${ }^{42}$

\subsection{Zusammenfassende Diskussion der molekularbiologi- schen Untersuchungen}

In diesem Aufsatz berichten wir den autosomalen Komposit-Genotyp des „Mädchens im spätmerowingerzeitlichen Kinderdoppelgrab von Frankfurt", dessen impliziter Nutzen in der qualitativen Absicherung unserer Befunde besteht. Für die kulturhistorische Fragestellung können die hier präsentierten Daten im Falle einer eventuellen historisch-archäologisch kontextualisierten Vergleichsprobe als Referenz für eine allfällige Rekonstruktion einer biologischen Verwandtschaft dienen.

Weiters darf an dieser Stelle nochmals der Fokus auf die beiden kontaminierten Proben vom Schädel des Mädchens gelegt werden: In diesem Fall konnte eine (mit an Sicherheit grenzender Wahrscheinlichkeit dem potentiellen Kontaminator ${ }^{43}$ zugeordnete) beinahe als historisch zu bezeichnende Kontamination durch eine bearbeitende Person nachgewiesen werden - was letztendlich die Notwendigkeit der Beprobung (und Analyse der DNA) aller bearbeitenden Personen für die Qualitätssicherung (Authentifizierung) historischer DNA-Ergebnisse verdeutlicht (vgl. Anm. 15). Die erhoffte Eingrenzung der bio-ethno-geographischen Zuordnung der weiblichen (mitochondrialen) Linie des Mädchens konnte im Rahmen dieser Untersuchungen nur bedingt erfüllt werden, auch wenn eine klare Zuordnung zur

39 M. Hüls, B. Kromer, in: Wamers 2015, 44-49. - Zur ${ }^{14}$ C-Problematik und zur archäologischen Datierung: E. Wamers, in: WAMERS 2015, 173-175.

40 Alt et al. 2014. - Amorim et al. 2018.

41 Walsh et al. 2014.

42 Chaitanya et al. 2017.

43 Aus Gründen des Datenschutzes und der Persönlichkeitsrechte unserer rezenten Probengeber verzichten wir auf die Darstellung des autosomalen und Y-chromosomalen DNA-Profils.
Haplogruppe U5b2a1a über die Sequenzierung des gesamten mitochondrialen Genoms erreicht wurde. Aus prähistorischer Perspektive zeichnet sich hier eher ein zentral- bis osteuropäisches Bild ab, wohingegen aus rezenter Sicht (vgl. Abb. 7) eher eine iberische Verortung naheliegend erscheint - letztendlich steht dieser Befund nicht im Widerspruch zu einer gesamteuropäischen Verortung. Dennoch muss (wie bereits oben in Anm. 33 angedeutet) größte Vorsicht bei der Abschätzung der bio-ethno-geographischen Zugehörigkeit von historischen Personen bzw. deren DNA-Daten anhand rezenter Verteilungsmuster (vgl. Anm. 32) zum Tragen kommen: In den im gegenständlichen Fall vorliegenden gut 1300 Jahren zwischen Studienobjekt und Referenzdatensatz kann sich das Verteilungsmuster z. B. durch Mutationen, also Veränderungen im Erbgut, oder aber auch bzw. vor allem durch Migrationsereignisse und -dynamiken, Naturkatastrophen und Seuchen signifikant verändern. Die berichteten Ergebnisse sind folglich bestenfalls als eine mit prinzipiellen Einschränkungen behaftete Abschätzung mit bedingter Belastbarkeit zu verstehen.

\section{Archäologisch-kulturhistorische Zusammenfassung}

(E. Wamers)

Die 2015 erschienene archäologische, antiquarische, naturwissenschaftliche und (kultur-)historische Neuauswertung des singulären „bi-rituellen Kinderdoppelgrabes“ aus Frankfurt hat mit der vorgelegten molekulargenetischen Analyse der menschlichen aDNA einen vorläufigen Abschluss gefunden. Zunächst ist es als Erfolg zu verbuchen, dass aus den sehr fragmentarisch erhaltenen Kleinkindknochen überhaupt verwertbare DNA extrahiert werden konnte. Aus den kremierten Knochenresten des zweiten, anthropologisch nicht geschlechtsbestimmten Kindes konnte leider keine DNA gewonnen werden, so dass dessen Geschlecht und weitere mögliche genetische Beziehungen zum Mädchen, die für die Gesamtbeurteilung der Grablege wichtige Aufschlüsse gebracht hätten, nicht bestimmt werden konnten. Durch das klare DNA-Profil des Mädchens sind nun aber weitere Vergleichsanalysen möglich, die mit zunehmendem Anwachsen der aDNA-Datenbanken relevant werden.

Ebenso waren weitergehende phänotypische Analysen des Mädchens, die seinerzeit für die Erstellung einer lebensbildlichen Rekonstruktion für eine Ausstellung ${ }^{44}$ erhofft wurden, nicht möglich, doch versprechen zu erwartende neue molekulargenetische Techniken hier für die Zukunft Ergebnisse.

44 Wamers 2013, 159-160, Abb. 108. - Vgl. auch Wamers 2015, 156-158 und Abb. 79 
Obwohl die antiquarisch-kulturhistorische Auswertung des Grabes manche Hinweise auf die „ethnische“ und kulturelle Verortung des Mädchens und seines mitbestatteten „Bei-Kindes“ erbracht hat, kann die Bestimmung des Haplotyps des Mädchens nur bedingt weiterhelfen: $\mathrm{Zu}$ klein ist die derzeitige internationale Datenbasis dieses alteuropäischen, zentral-osteuropäischen Typs, der nach derzeitiger Datenlage aber auch in der Nord- und Ostseeküstenzone sowie in Skandinavien vertreten ist. Für die nähere Zukunft ist ein Anwachsen dieser Basis zu erwarten, wodurch die kulturhistorische Positionierung des Frankfurter Mädchens und seiner Familie im frühen 8. Jh. weitaus prägnanter sichtbar sein wird.

\section{Danksagung}

Dank gebührt der TuBa-Privatstiftung sowie Professor Fabio Monticelli und der Gerichtsmedizin GmbH für die finanzielle Unterstützung des Projektes. Für die große Bereitschaft der Kontaktpersonen zur Abgabe einer anonymen DNA-Probe sei allen sehr herzlich gedankt, insbesondere Erwin Hahn, der seiner namentlichen Nennung an dieser Stelle ausdrücklich zugestimmt hat.

\section{Literatur}

Alt et al. 2014

K. W. Alt, C. Knipper, D. Peters, W. Müller, A.-F. Maurer, I. Kollig, N. Nicklisch, C. Müller, S. Karimnia, G. Brandt, C. Roth, M. Rosner, B. Mende, B. R. Schöne, T. VidA, U. von Freeden, Lombards on the move: an integrative study of the migration period cemetery at Szólád, Hungary, PLoS ONE 9/11, 2014, e110793. doi: 10.1371/journal.pone.0110793.

AMorim et al. 2018

C. E. G. Amorim, S. Vai, C. Posth, A. Modi, I. Koncz, S. Hakenbeck, M. C. La Rocca, B. Mende, D. Вовo, W. Pohl, L. Pejrani Baricco, E. Bedini, P. Francalacci, C. Giostra, T. Vida, D. Winger, U. von Freeden, S. Ghirotto, M. Lari, G. Barbujani, J. Krause, D. Caramelli, P. J. Geary, K. R. VeerAMAH, Understanding $6^{\text {th }}$-century barbarian social organization and migration through paleogenomics, Nature Communications 9, 2018, 3547. doi: 10.1038/s41467-018-06024-4.

ANDREws et al. 1999

R. M. Andrews, I. Kubacka, I. P. F. Chinnery, R. N. Lightowlers, D. M. Turnbull, N. Howell, Reanalysis and revision of the Cambridge reference sequence for human mitochondrial DNA, Nature Genetics 23/2, 1999, 147. doi: 10.1038/13779.

Cemper-Kiesslich, Neuhuber, Schwarz 2010

J. Cemper-Kiesslich, F. Neuhuber, R. Schwarz, „Gene aus alten Knochen“ - Alte DNA \& molekulare Archäologie: Ein Überblick über die Methodik der molekularbiologischen Spurenanalytik an biogenen Überresten mit einem praktischen Leitfaden für die Probennahme und Aufbewahrung. In: J. Cemper-KiessLich, F. Lang, K. Schaller, C. Uhlir, M. Unterwurzacher (Hrsg.), Primus Conventus Austriacus Archaeometriae. Scientiae Naturalis Ad Historiam Hominis Antiqui Investigandam MMIX: Tagungsband zum Ersten Österreichischen Archäometriekongress, 15.-17. Mai 2009. ArchaeoPlus 1, Salzburg 2010, 24-41.

\section{Cemper-Kiesslich, Schwarz, Neuhuber 2011}

J. Cemper-Kiesslich, R. Schwarz, F. Neuhuber, Dialysis vs. Qiagen M48: two alternative procedures for purifying ancient DNA from bone and teeth extracts. In: J. Cemper-Kiesslich (Hrsg.), Tagungsband zum Zweiten Österreichischen Archäometriekongress, 13.-14. Mai 2010. ArchaeoPlus 2, Salzburg 2011,121-124.

Cemper-Kiesslich et al. 2021

J. Cemper-Kiesslich, P. Kralj, R. Jung, F. Kanz, W. Parson, Ancient DNA from Punta di Zambrone: minute traces of ancient DNA or 'much ado about nothing'? In: R. Jung (Hrsg.), Punta di Zambrone I: 1200 BCE - a Time of Breakdown, a Time of Progress in Southern Italy and Greece. Oriental and European Archaeology 17, Wien 2021, 267-276.

Chaitanya et al. 2017

L. Chaitanya, I. Z. Pajnic, S. Walsh, J. Balazic, T. Zupanc, M. KAYSER, Bringing colour back after 70 years: predicting eye and hair colour from skeletal remains of World War II victims using the HIrisPlex system, Forensic Science International: Genetics 26, 2017, 48-57. doi: 10.1016/j.fsigen.2016.10.004.

Chyleński et al. 2017

M. Chyleński, A. Juras, E. Ehler, H. Malmström, J. Piontek, M. Jakobsson, A. Marciniak, M. Dabert, Late Danubian mitochondrial genomes shed light into the Neolithisation of central Europe in the $5^{\text {th }}$ millennium BC, BMC Evolutionary Biology 17/1, 2017, 80. doi: 10.1186/s12862-017-0924-0.

\section{HAMPEL 1994}

A. Hampel, Der Kaiserdom zu Frankfurt am Main. Beiträge zum Denkmalschutz in Frankfurt am Main 8, Nußloch 1994.

HaRTMANn 2002

W. Hartmann, Ludwig der Deutsche. Darmstadt 2002.

Helm, Neuhuber, Cemper-Kiesslich 2020

K. Helm, F. Neuhuber, J. Cemper-Kiesslich, Kasuistik: Identifizierung eines Neugeborenen nach 36 Jahren im Erdgrab, Archiv für Kriminologie 246, 2020, 113-120.

JURAs et al. 2017a

A. Juras, M. Chyleński, M. Krenz-Niedbaea, H. Malmström, E. Ehler, Ł. Pospieszny, S. Łukasik, J. Bednarczyk, J. PionTEK, M. Jakobsson, M. DAbert, Investigating kinship of Neolithic post-LBK human remains from Krusza Zamkowa, Poland using ancient DNA, Forensic Science International: Genetics 26, 2017, 30-39. doi: 10.1016/j.fsigen.2016.10.008.

Juras et al. 2017b

A. Juras, M. Krzewińska, A. G. Nikitin, E. Ehler, M. Chyleński, S. Łukasik, M. Krenz-Niedbata, V. Sinika, J. Piontek, S. IvaNOVA, M. DABert, A. GÖTherström, Diverse origin of mitochondrial lineages in Iron Age Black Sea Scythians, Scientific Report 7, 2017, 43950. doi: 10.1038/srep43950.

Косн 1999

U. Косн, Nordeuropäisches Fundmaterial in Gräbern Süddeutschlands rechts des Rheins. In: U. von FreEden, U. Koch, A. WIECZOREK (Hrsg.), Völker an Nord- und Ostsee und die Franken. Akten des 48. Sachsensymposiums in Mannheim vom 7. bis 11. September 1997. Bonn 1999, 175-194.

Косн 2013

U. Косн, Die weibliche Elite im Merowingerreich - Königinnen, Hofherrinnen und Töchter. In: E. Wamers, P. Perin (Hrsg.), Königinnen der Merowinger. Adelsgräber aus den Kirchen von Köln, Saint-Denis, Chelles und Frankfurt am Main (Ausstellungskatalog Frankfurt - Köln 2012-2013), 2. Auflage. Regensburg 2013, 37-58. 


\section{KrUTZLER 2009}

G. Krutzler, Fremdwahrnehmungen in der frühmittelalterlichen Ethnographie. Unveröffentlichte Dissertation, Universität Wien 2009. doi: 10.25365/thesis.6784.

MalyarchuK et al. 2010

B. Malyarchuk, M. Derenko, T. Grzybowski, M. Perkova, U. Rogalla, T. Vanecek, I. Tsybovsky, The peopling of Europe from the mitochondrial haplogroup U5 perspective, PLoS ONE 5/4, 2010, e10285. doi: 10.1371/journal.pone.0010285.

Oversti et al. 2017

S. Oversti, P. Onkamo, M. Stoljarova, B. Budowle, A. SajantiLA, J. U. PALO, Identification and analysis of mtDNA genomes attributed to Finns reveal long-stagnant demographic trends obscured in the total diversity, Scientific Reports 7, 2017, 6193. doi: 10.1038/s41598-017-05673-7.

PARSON et al. 2013

W. Parson, C. Strobl, G. Huber, B. Zimmermann, S. M. Gomes, L. Souto, L. Fendt, R. Delport, R. Langit, S. Wootton, R. LAgACÉ, J. IRwin, Evaluation of next generation mtGenome sequencing using the Ion Torrent Personal Genome Machine (PGM), Forensic Science International: Genetics 7, 2013, 543549. doi: 10.1016/j.fsigen.2013.06.003.

Pinhasi et al. 2015

R. Pinhasi, D. Fernandes, K. Sirak, M. Novak, S. Connell, S. Alpaslan-Roodenberg, F. Gerritsen, V. Moiseyev, A. Gromov, P. Raczky, A. Anders, M. Pietrusewsky, G. Rollefson, M. Jovanovic, H. Trinhhoang, G. Bar-Oz, M. Oxenham, H. Matsumura, M. Hofreiter, Optimal ancient DNA yields from the inner ear part of the human petrous bone, PLoS ONE 10/6, 2015, e0129102. doi: 10.1371/journal.pone.0129102.

RENAUd et al. 2015

G. Renaud, V. Slon, A. T. Duggan, J. Kelso, Schmutzi: estimation of contamination and endogenous mitochondrial consensus calling for ancient DNA, Genom Biology 16, 2015, 224. doi: 10.1186/s13059-015-0776-0.

RisTOW 2020

S. Ristow, Rekonstruktion der Frankfurter Pfalz: Möglichkeiten, Fragestellungen und Probleme nach den Ergebnissen der Ausgrabungen der letzten 70 Jahre. In: C. Ehlers, H. Grewe (Hrsg.), Mittelalterliche Paläste und die Reisewege der Kaiser: Neue Entdeckungen in den Orten der Macht an Rhein und Main. Oppenheim 2020, 52-75.

SIPPEL 1989

K. Sippel, Die frühmittelalterlichen Grabfunde in Nordhessen. Materialien zur Vor- und Frühgeschichte von Hessen 7, Wiesbaden 1989.

STROBL et al. 2018

C. Strobl, M. Eduardoff, M. M. Bus, M. Allen, W. Parson, Evaluation of the precision ID whole MtDNA genome panel for forensic analyses, Forensic Science International: Genetics 35, 2018, 21-25. doi: 10.1016/j.fsigen.2018.03.013.

WALSH et al. 2014

S. Walsh, L. Chaitanya, L. Clarisse, L. Wirken, J. DrausBarini, L. Kovatsi, H. Maeda, T. Ishikawa, T. Sijen, P. DE KnijfF, W. Branicki, F. LiU, M. Kayser, Developmental validation of the HIrisPlex system: DNA-based eye and hair colour prediction for forensic and anthropological usage, Forensic Science International: Genetics 9, 2014, 150-161. doi: 10.1016/j. fsigen.2013.12.006.
WAMERS 2013

E. Wamers, Das Kinderdoppelgrab unter der Frankfurter Bartholomäuskirche. In: E. Wamers, P. Perin (Hrsg.), Königinnen der Merowinger. Adelsgräber aus den Kirchen von Köln, Saint-Denis, Chelles und Frankfurt am Main (Ausstellungskatalog Frankfurt - Köln 2012-2013), 2. Auflage. Regensburg 2013, 161-182.

WAMERS 2015

E. Wamers, mit Beiträgen von T. Flügen, R. Goedecker-Ciolek, S. Greiff, S. Hartmann, M. Hüls, N. Krohn, B. Kromer, S. Martins, B. Nowak-Böck, I. Schneebauer-Meissner, A. Pesch, G. Possnert, N.-J. Rebach, G. Schneider, M. Schweissing, F. Ströвele, Franconofurd 2: Das bi-rituelle Kinderdoppelgrab der späten Merowingerzeit unter der Frankfurter Bartholomäuskirche („Dom“). Archäologische und naturwissenschaftliche Untersuchungen. Schriften des Archäologischen Museums Frankfurt 22/2, Regensburg 2015.

WINTERGERST 2007

M. Wintergerst, mit einem Beitrag von E. Wamers, Franconofurd 1: Die Befunde der karolingisch-ottonischen Pfalz aus den Frankfurter Altstadtgrabungen 1953-1993. Schriften des Archäologischen Museums Frankfurt 22/1, Frankfurt am Main 2007.

Jan Cemper-Kiesslich

Universität Salzburg

Interfakultärer Fachbereich Gerichtsmedizin und Fachbereich Altertumswissenschaften sowie CAMAS (Center of Applied Molecular Archaeology) Ignaz-Harrer-Straße 79 5020 Salzburg

Österreich

jan.kiesslich@plus.ac.at orcid.org/0000-0002-9108-0055

Christina Amory Medizinische Universität Innsbruck Institut für Gerichtliche Medizin Müllerstraße 44 6020 Innsbruck Österreich christina.amory@i-med.ac.at

Walther Parson Medizinische Universität Innsbruck Institut für Gerichtliche Medizin Müllerstraße 44 6020 Innsbruck

Österreich walther.parson@i-med.ac.at

Egon Wamers

Deutschland egon.wamers@botmail.de 